\title{
Fabrication of $\mathrm{Si}_{3} \mathrm{~N}_{4}$ Nanocrystals and Nanowires Using PECVD
}

\author{
Jingwei Song, Xiying Ma, Wang Zui, Chen Wei, and Zhongpin Chen \\ School of Mathmatics and Physics, Suzhou University of Science and Technology, 1701 Binhe Road, Suzhou, 215011 Jiangsu, China \\ Correspondence should be addressed to Xiying Ma, maxy@usx.edu.cn
}

Received 26 October 2009; Accepted 9 March 2010

Academic Editor: Dao Hua Zhang

Copyright () 2010 Jingwei Song et al. This is an open access article distributed under the Creative Commons Attribution License, which permits unrestricted use, distribution, and reproduction in any medium, provided the original work is properly cited.

\begin{abstract}
$\mathrm{Si}_{3} \mathrm{~N}_{4}$ nanowires and nanocrystals were prepared on $\mathrm{Si}$ substrates with or without Fe catalyst using silane $\left(\mathrm{SiH}_{4}\right)$ and nitrogen $\left(\mathrm{N}_{2}\right)$ as reactive gases through plasma-enhanced chemical vapor deposition (PECVD) technology. With Fe catalyst, $\mathrm{Si}_{3} \mathrm{~N}_{4}$ nanowires were developed, indicating that Fe catalyst played a role for $\mathrm{Si}_{3} \mathrm{~N}_{4}$ molecules directionally depositing into strings. The density of the nanowires is closely related to the density of Fe catalyst. When the density of Fe ions on the substrate was decreased remarkably, a smooth superlong $\mathrm{Si}_{3} \mathrm{~N}_{4}$ nanowire with $12 \mu \mathrm{m}$ in length was fabricated. Having analyzed the growth mechanism, a growth model for $\mathrm{Si}_{3} \mathrm{~N}_{4}$ nanowires was developed. The growth of $\mathrm{Si}_{3} \mathrm{~N}_{4}$ nanocrystallines was attributed to be a vapor-solid (V-S) deposition process.
\end{abstract}

\section{Introduction}

Silicon nitride $\left(\mathrm{Si}_{3} \mathrm{~N}_{4}\right)$ is a versatile material, which has been widely used in ceramic engines, microelectronics, nuclear power engineering, space science [1-3], and other fields due to its many excellent properties, such as high temperature resistance, high strength and modulus, and good chemical stability properties. Moreover, nanoscaled $\mathrm{Si}_{3} \mathrm{~N}_{4}$ materials, quantum dots [4-6], nanotubes [7], nanowires $[8,9]$, and thin nanofilms [10] have superior photoelectric $[11]$ and mechanical properties $[12,13]$ for the quantum confinement effects, and therefore, the improvement in device and nanocomposite performance can be predicted [14]. Various techniques, such as catalyst-assistant synthesis of a polysilazane [15], direct nitridation process [16], amorphous silicon nitride nanopowder nitridation [17], si-containing compounds carbothermal reductionnitridation [18], chemical vapor deposition (CVD) [19], and plasma assisted chemical vapor deposition (PECVD) are used to prepare $\mathrm{Si}_{3} \mathrm{~N}_{4}$ nanomaterials. Among these available techniques, PECVD has many advantages over others. A main reason is that the chemical groups in plasma has a very high energy, which can remarkably low the reaction temperature that is very useful for synthesis of both nanocrystals and nanowires. Another significant advantage is the capability of fast deposition high quality of nanocrystals and nanowires on large area substrates. Now it has been used increasingly to synthesize various semiconductor films [20]. In this paper, using PECVD we have fabricated $\mathrm{Si}_{3} \mathrm{~N}_{4}$ nanowires and nanocrystals on $\mathrm{Si}$ substrates with or without Fe catalyst, respectively. By decreasing the number of Fe catalyst on Si substrates to a minute, single dispersed $\mathrm{Si}_{3} \mathrm{~N}_{4}$ nanowires can be obtained. Based on the analysis of scanning electronic microscopy (SEM) and Xray diffraction (XRD), we developed a growth model for $\mathrm{Si}_{3} \mathrm{~N}_{4}$ nanowires and discussed the growth mechanism as well.

\section{Experiment}

The studied samples were prepared on n-type Si (100) wafers by using PECVD system. Two substrates were cleaned ultrasonically with a sequence of acetone, ethanol, and deionized water, and dried by blowing $\mathrm{N}_{2}$. One was directly placed in the vacuum chamber; the other was coated Fe catalyst by dipping into a weak solution of $\mathrm{FeCl}_{2}$ with some time and then put into the chamber as well. The reactive gases were silane diluted with nitrogen gas $\left(10 \% \mathrm{SiH}_{4}+90 \% \mathrm{~N}_{2}\right)$ and $\operatorname{Ar}(99.999 \%)$, with a volume ratio of $1: 4$. Prior to the deposition, a pretreatment of the samples in hydrogen plasma was performed at about $500^{\circ} \mathrm{C}$ for 10 minutes. At deposition, the substrate temperature was fixed between $400-500^{\circ} \mathrm{C}$, the working pressure was kept in $40-50 \mathrm{~Pa}$, and 


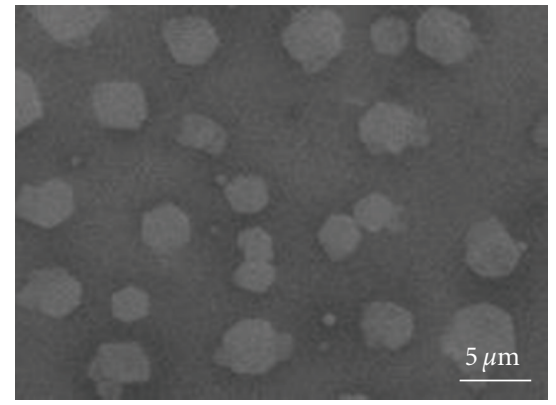

(a)

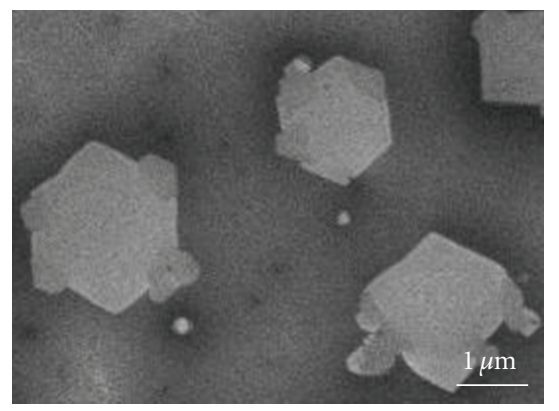

(b)

Figure 1: (a) A SEM image of $\mathrm{Si}_{3} \mathrm{~N}_{4}$ crystals; (b) a magnification picture.

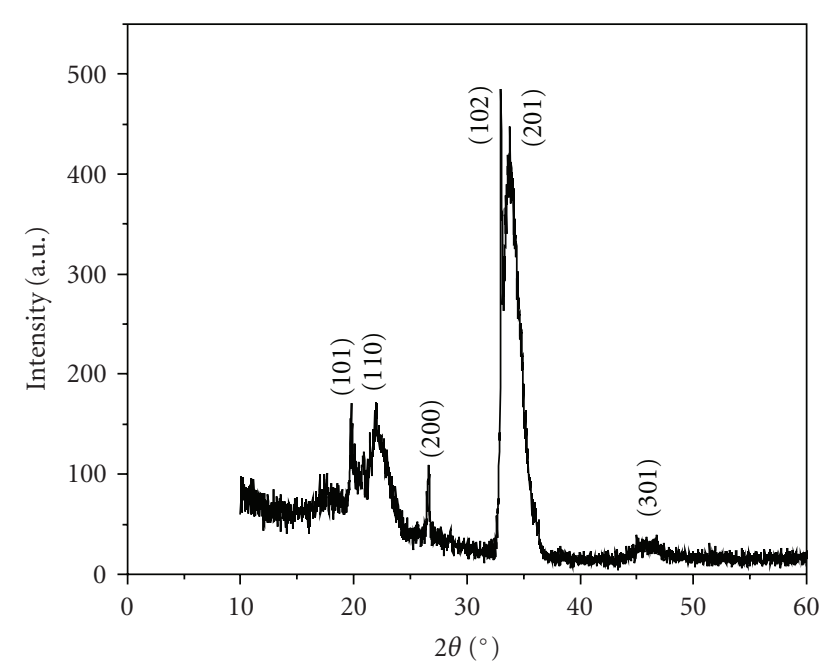

FIgURE 2: An XRD pattern of as-synthesized $\mathrm{Si}_{3} \mathrm{~N}_{4}$ nanoparticles.

the plasma power was about $50 \mathrm{~W}$ under an applied bias of $800 \mathrm{~V}$.

In the deposition, $\mathrm{SiH}_{4}, \mathrm{~N}_{2}$, and Ar were initially decomposed to a mixture state of $\mathrm{Si}, \mathrm{H}, \mathrm{N}, \mathrm{Ar}, \mathrm{H}_{2}$, and $\mathrm{N}_{2}$ under the large bias. This mixture state is referred to as a plasma state, in which the chemical groups consisted of atoms and molecules have very high energy. A new matter of SiN was compounded feasibly at low temperatures when $\mathrm{Si}$ and $\mathrm{N}$ atoms were combined together. With $\mathrm{SiN}$ molecules condensed continually on the substrates, $\mathrm{Si}_{3} \mathrm{~N}_{4}$ nanocrystals or nanowires were developed. The decomposition and compound processes of the experiment can be described as the following chemical reactions:

$$
\begin{aligned}
& \mathrm{SiH}_{4 \text { (gas) }} \stackrel{\text { decomposition }}{\longrightarrow}\left[\mathrm{SiH}_{m}\right] \longrightarrow \mathrm{Si}+m[\mathrm{H}] \text {, } \\
& \mathrm{Si}+2 \mathrm{~N}_{2} \longrightarrow \alpha-\mathrm{Si}_{3} \mathrm{~N}_{4} \text {. }
\end{aligned}
$$

The experiment was carried out for 1 hour. The samples were removed from the chamber when they cooled to room temperature. The morphology and structure of the samples were characterized by field emission scanning electron microscope (FESEM) and X-ray diffraction (XRD).

\section{Results and Discussion}

Figure 1(a) shows a surface SEM image of the sample deposited on Si substrate free of Fe catalyst at temperature of $400^{\circ} \mathrm{C}$ and pressure of $40 \mathrm{~Pa}$. It can be seen that many cubic crystals are scattered homogeneously on the picture. The crystals take almost identical shape, that is, a normal tetrahedron structure, as clearly shown in the enlarged picture Figure 1(b). The tetrahedron structure shows that the deposited $\mathrm{Si}_{3} \mathrm{~N}_{4}$ nanocrystals are characteristic of the typical diamond structure. The size of crystals also is nearly uniform, with a mean side length of $1 \mu \mathrm{m}$. The X-ray diffraction pattern of the sample is shown in Figure 2. The diffraction peaks from $19.7,22.0,26.7,32.9,33.69$, and $39.6^{\circ}$ correspond to (101), (110), (200), (102), (201), and (301) of $\mathrm{Si}_{3} \mathrm{~N}_{4}$ crystals facets, respectively. The peaks of (101) and (110) are relatively wide for some amorphous particles attached on the crystals. It confirms that the crystals are $\mathrm{Si}_{3} \mathrm{~N}_{4}$ polycrystals.

For Si substrate coated with Fe catalyst by dipping in a weak $\mathrm{FeCl}_{2}$ solution for 48 hours, $\mathrm{Si}_{3} \mathrm{~N}_{4}$ nanowires were developed, as shown in the SEM images of Figure 3. Many tree-like structures made up of thin branches are distributed on the picture. We referred to the thin branches here as $\mathrm{Si}_{3} \mathrm{~N}_{4}$ nanowire, on which many newly nucleated nanoparticles attached. The diameter of the nanorires is basically uniform, with a size of $0.20 \mu \mathrm{m}$; but the length is various, from 5 to $20 \mu \mathrm{m}$. Figure $3(\mathrm{~b})$ is a magnification picture, where the nanowires with many $\mathrm{Si}_{3} \mathrm{~N}_{4}$ nanoparticles are clearly seen. We note that one of the nanowires broke off, wich might be caused by the unevenly stressing and large surface tension for it is too long.

$\mathrm{Si}_{3} \mathrm{~N}_{4}$ nanowires and nanoparticles were grown on $\mathrm{Si}$ substrates with or without Fe catalyst under the same deposition conditions, indicating that Fe catalyst has a promote action for preferring orientationally growing, which plays a key role in the synthesis of $\mathrm{Si}_{3} \mathrm{~N}_{4}$ nanowires. It has been reported that $\mathrm{Fe}$ ions have a directional action in the growing of nanotube and nanowires materials [21]. To explore the growth mechanism, we developed a growth model for $\mathrm{Si}_{3} \mathrm{~N}_{4}$ nanowires, as shown in Figure 4 . Fe ions have catalysis and play the centers of nucleation to accelerate the nucleation of $\mathrm{Si}_{3} \mathrm{~N}_{4}$ that absorbed on Fe ions by Van der Waals attractive force. With a strong Van der Waals attractive force, $\mathrm{Fe}^{2+}$ ions can promote $\mathrm{Si}_{3} \mathrm{~N}_{4}$ molecules growing in a preferred 


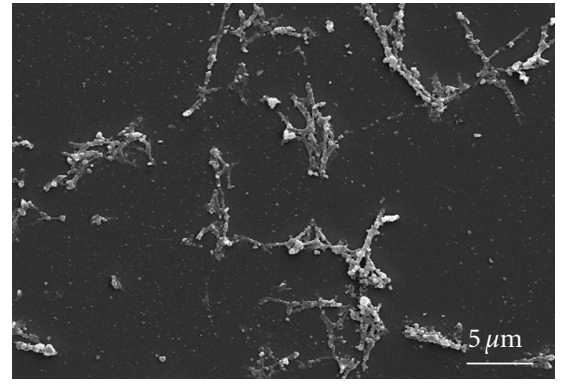

(a)

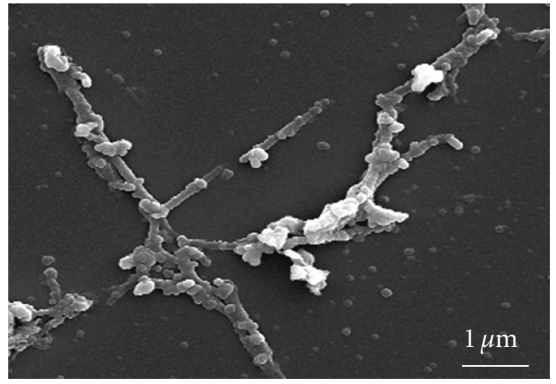

(b)

FIGURE 3: (a) A SEM image of $\mathrm{Si}_{3} \mathrm{~N}_{4}$ nanowires deposited on Fe catalyst coated Si substrate treated for 48 hours; (b) a magnification picture, the nanowires with many $\mathrm{Si}_{3} \mathrm{~N}_{4}$ particles are characteristic of a tree-like structure.

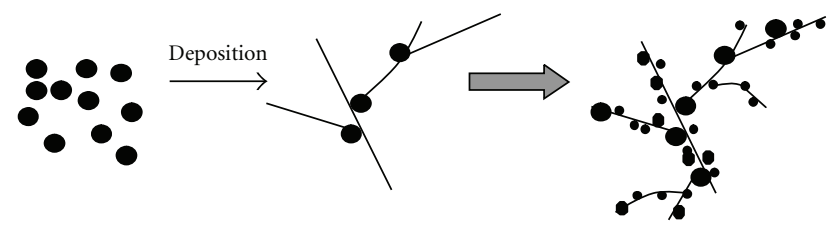

Figure 4: A growth model of $\mathrm{Si}_{3} \mathrm{~N}_{4}$ nanowires.

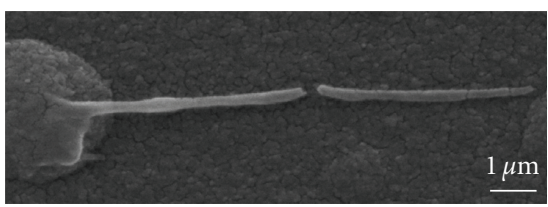

(a)

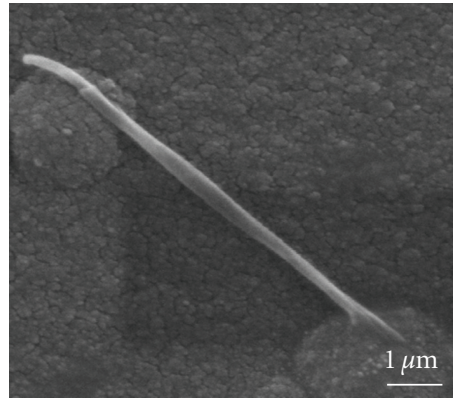

(b)

FIGURE 5: (a) A SEM image of single superlong $\mathrm{Si}_{3} \mathrm{~N}_{4}$ nanowire growing on $\mathrm{Fe}$ catalyst coated Si substrate treated for 4 hours; (b) another $\mathrm{Si}_{3} \mathrm{~N}_{4}$ nanowire taken in other place of the same sample.

orientation by fixing and decreasing the mobility of them. With deposition, small $\mathrm{Si}_{3} \mathrm{~N}_{4}$ nanowires are formed and finally developed into long nanowires. Through branching in various directions, many nanowires with tree-like structure are finally completed on the substrate.

Many $\mathrm{Si}_{3} \mathrm{~N}_{4}$ nanoparticles and amorphous are attached on the nanowires, which make the nanowires not very well. The particles are caused by too many $\mathrm{Si}_{3} \mathrm{~N}_{4}$ molecules nucleated on the nanowires due to a large number of Fe ions on Si wafers. To reduce the useless particles, we decreased the concentration of Fe ions by shorting the dipping time of
Si wafer in $\mathrm{FeCl}_{2}$ solution to 4 hours. In addition, to diminish the amorphous and to enhance the crystallization, the reactive pressure was decreased to $40 \mathrm{~Pa}$ and the temperature was increased to $500^{\circ} \mathrm{C}$. As shown in Figure 5(a), a smooth, single, superlong $\mathrm{Si}_{3} \mathrm{~N}_{4}$ nanowire without any nanoparticles is developed on the substrate. Like a tree growing from a large root, the superlong nanowire grows from a large spherical cluster. The total length is about $12 \mu \mathrm{m}$, and the diameter is about $0.25 \mu \mathrm{m}$, but becomes thinner from the bottom to the top. Moreover, the nanowire broke off at its middle, just at the mass center of the nanowire. Thus the gap may be caused by the gravity and large surface tension because the nanowire protrudes out the substrate with a slope than lies on it. Figure 5(b) is another single nanowire picture taken from other place of the sample. It grows from a cluster and ends to another one, like a long bridge between two clusters. The nanowire twisted twice showing that there is a large stress existing during growth. Obviously, by decreasing the concentration of $\mathrm{Fe}$ ions and the reactive pressure, the density of nanowires is significantly decreased, and the useless nanoparticles and amorphous are hardly seen on the nanowires. As a result, superlong high quality $\mathrm{Si}_{3} \mathrm{~N}_{4}$ nanowires are obtained.

Since there are no liquid droplets at the tips of nanowires, which were typically observed in vapor-liquid-solid (VLS) growth mechanism $[22,23]$, hence in our experiment the growth mechanism of $\mathrm{Si}_{3} \mathrm{~N}_{4}$ nanocrystals can be assigned to a vapor-solid (V-S) process.

\section{Conclusion}

A superlong single $\mathrm{Si}_{3} \mathrm{~N}_{4}$ nanowire without any useless particles has been synthesized on Fe coated Si substrate using PECVD system by optimize deposition conditions including temperature and pressure. Based on the observation of SEM) we developed a model for $\mathrm{Si}_{3} \mathrm{~N}_{4}$ nanowires growing, and the growth mechanism is attributed to a vapor-solid (V-S) deposition process.

\section{Acknowledgments}

This work was supported in parts by the National Natural Science Foundation of China (no. 60776004, 
60976071 ) and the scientific project of Shaoxing city (no. 2008R40G2180006).

\section{References}

[1] M. Herrmann, C. Boberski, G. Michael, G. Putzky, and W. Hermel, "Redistribution of the liquid phase during sintering of silicon nitride," Journal of Materials Science Letters, vol. 12, no. 20, pp. 1641-1643, 1993.

[2] G. Ziegler, J. Heinrich, and G. Wötting, "Relationships between processing, microstructure and properties of dense and reaction-bonded silicon nitride," Journal of Materials Science, vol. 22, no. 9, pp. 3041-3086, 1987.

[3] M. J. Hoffmann and G. Petzow, "Microstructural design of $\mathrm{Si}_{3} \mathrm{~N}_{4}$ based ceramics," in Materials Research Society Symposium Proceedings, vol. 287, pp. 3-14, Boston, Mass, USA, December 1993.

[4] C. Livermore, C. H. Crouch, R. M. Westervelt, K. L. Campman, and A. C. Gossard, "The Coulomb blockade in coupled quantum dots," Science, vol. 274, no. 5291, pp. 1332-1335, 1996.

[5] S. Tarucha, "Transport in quantum dots: observation of atomlike properties," MRS Bulletin, vol. 23, no. 2, pp. 49-53, 1998.

[6] A. J. Nozik and O. I. Mićić, "Colloidal quantum dots of III-V semiconductors," MRS Bulletin, vol. 23, no. 2, pp. 24-30, 1998.

[7] G. G. Tibbetts, "Vapour grown carbon fibers," Carbon Fibres Filaments and Composites, Kluwer Academic Publishers, Amsterdam, The Netherlands, 1990.

[8] Y. Cui and C. M. Lieber, "Functional nanoscale electronic devices assembled using silicon nanowire building blocks," Science, vol. 291, no. 5505, pp. 851-853, 2001.

[9] W. Yang, Z. Xie, J. Li, H. Miao, L. Zhang, and L. An, "Ultralong single-crystalline $\alpha-\mathrm{Si}_{3} \mathrm{~N}_{4}$ nanowires: derived from a polymeric precursor," Journal of the American Ceramic Society, vol. 88, no. 6, pp. 1647-1650, 2005.

[10] D.-H. Xiang, M. Chen, Y.-P. Ma, and F.-H. Sun, "Adhesive strength of CVD diamond thin films quantitatively measured by means of the bulge and blister test," Journal of University of Science and Technology Beijing, Mineral, Metallurgy, Material, vol. 15, no. 4, pp. 474-479, 2008.

[11] L. Zhang, H. Jin, W. Yang, Z. Xie, H. Miao, and L. An, "Optical properties of single-crystalline $\alpha-\mathrm{Si}_{3} \mathrm{~N}_{4}$ nanobelts," Applied Physics Letters, vol. 86, no. 6, Article ID 061908, 3 pages, 2005.

[12] A. M. Morales and C. M. Lieber, "A laser ablation method for the synthesis of crystalline semiconductor nanowires," Science, vol. 279, no. 5348, pp. 208-211, 1998.

[13] L.-W. Yin, Y. Bando, Y.-C. Zhu, and Y.-B. Li, "Synthesis, structure, and photoluminescence of very thin and wide alpha silicon nitride $\left(\alpha-\mathrm{Si}_{3} \mathrm{~N}_{4}\right)$ single-crystalline nanobelts," Applied Physics Letters, vol. 83, no. 17, pp. 3584-3586, 2003.

[14] G. Gundiah, G. V. Madhav, A. Govindaraj, Md. M. Seikh, and C. N. R. Rao, "Synthesis and characterization of silicon carbide, silicon oxynitride and silicon nitride nanowires," Journal of Materials Chemistry, vol. 12, no. 5, pp. 1606-1611, 2002.

[15] W. Yang, Z. Xie, H. Miao, L. Zhang, H. Ji, and L. An, "Synthesis of single-crystalline silicon nitride nanobelts via catalyst-assisted pyrolysis of a polysilazane," Journal of the American Ceramic Society, vol. 88, no. 2, pp. 466-469, 2005.

[16] H. Y. Kim, J. Park, and H. Yang, "Synthesis of silicon nitride nanowires directly from the silicon substrates," Chemical Physics Letters, vol. 372, no. 1-2, pp. 269-274, 2003.
[17] H. Zhang, S. Zhang, S. Pan, and J. Hou, "Synthesis and characterization of several $\alpha$-silicon nitride nanostructures," Journal of the American Ceramic Society, vol. 88, no. 3, pp. 566$569,2005$.

[18] C. N. R. Rao, G. Gundiah, F. L. Deepak, A. Govindaraj, and A. K. Cheetham, "Carbon-assisted synthesis of inorganic nanowires," Journal of Materials Chemistry, vol. 14, no. 4, pp. 440-450, 2004.

[19] Q. Wei, C. Xue, Z. Sun, et al., "Fabrication of large-scale $\alpha$ $\mathrm{Si}_{3} \mathrm{~N}_{4}$ nanotubes on $\mathrm{Si}\left(\begin{array}{lll}1 & 1 & 1\end{array}\right)$ by hot-wall chemical-vapordeposition with the assistance of $\mathrm{Ga}_{2} \mathrm{O}_{3}$," Applied Surface Science, vol. 229, no. 1-4, pp. 9-12, 2004.

[20] D. Hegemann, H. Brunner, and C. Oehr, "Evaluation of deposition conditions to design plasma coatings like $\mathrm{SiO}_{x}$ and a-C:H on polymers," Surface and Coatings Technology, vol. 174-175, pp. 253-260, 2003.

[21] H. Dai, J. Kong, C. Zhou, et al., "Controlled chemical routes to nanotube architectures, physics, and devices," Journal of Physical Chemistry B, vol. 103, no. 51, pp. 11246-11255, 1999.

[22] F. Gao, W. Yang, Y. Fan, and L. An, "Mass production of very thin single-crystal silicon nitride nanobelts," Journal of Solid State Chemistry, vol. 181, no. 1, pp. 211-215, 2008.

[23] R. S. Wagner and W. C. Ellis, "Vapor-liquid-solid mechanism of single crystal growth," Applied Physics Letters, vol. 4, no. 5, pp. 89-90, 1964. 

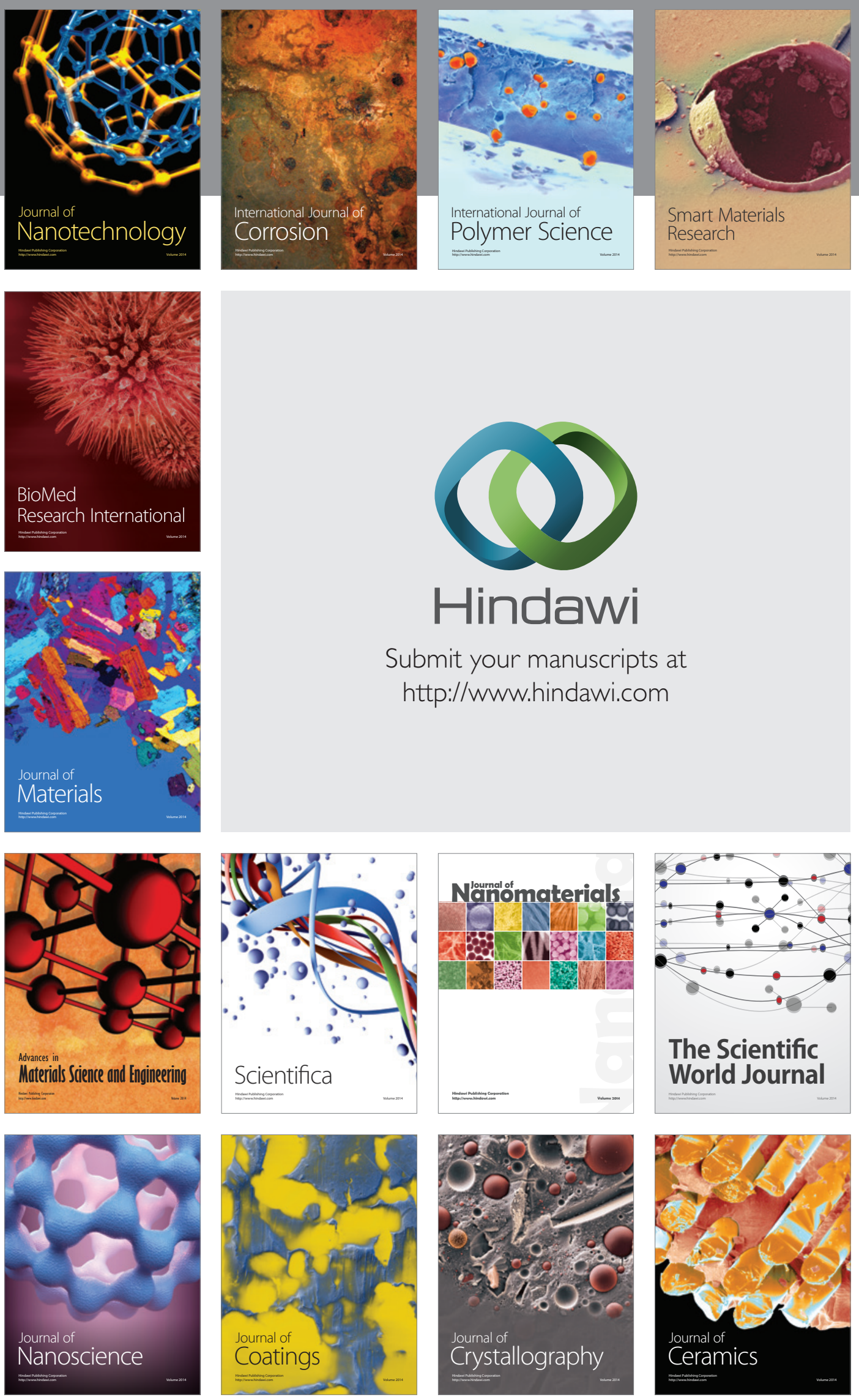

The Scientific World Journal

Submit your manuscripts at

http://www.hindawi.com

\section{World Journal}

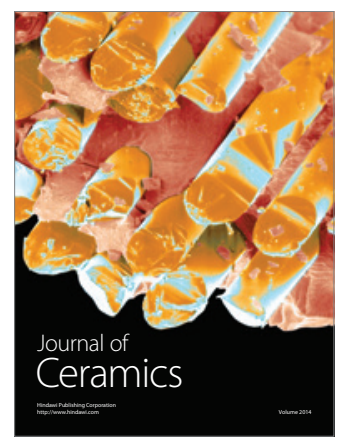

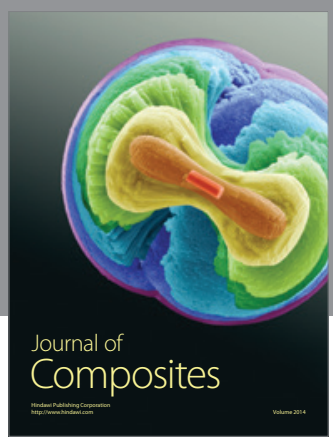
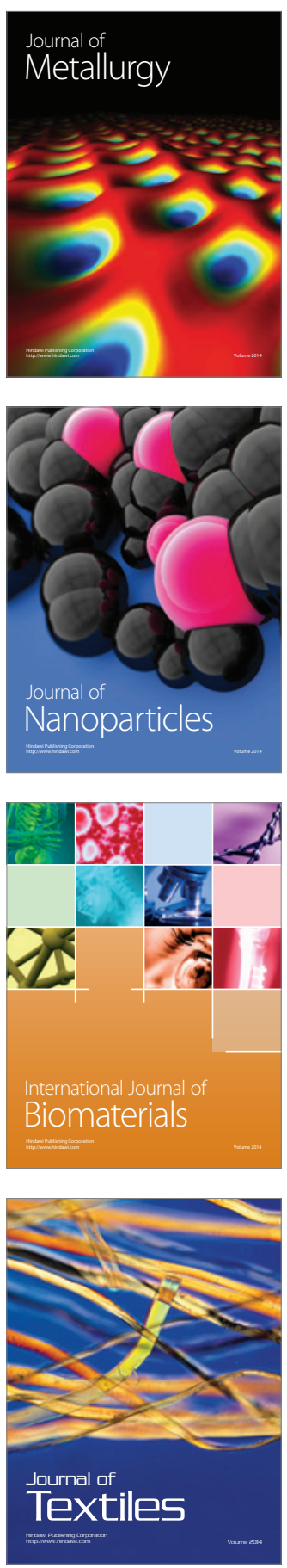